\title{
Photodynamic inactivation of a multispecies biofilm using curcumin and LED light
}

\author{
Cristiane Campos Costa Quishida ${ }^{1}$ - Ewerton Garcia De Oliveira Mima ${ }^{2}$. \\ Janaina Habib Jorge $^{2}$ - Carlos Eduardo Vergani ${ }^{2}$ - Vanderlei Salvador Bagnato ${ }^{3}$. \\ Ana Cláudia Pavarina ${ }^{2}$
}

Received: 14 October 2015 / Accepted: 20 April 2016/Published online: 28 April 2016

(C) Springer-Verlag London 2016

\begin{abstract}
This study evaluated the potential of curcuminmediated antimicrobial photodynamic inactivation (API) on multispecies biofilms of Candida albicans, Candida glabrata, and Streptococcus mutans of different ages. Acrylic samples $(n=480)$ were made with standardized rough surfaces and incubated with bacteria and yeast for 24 or $48 \mathrm{~h}$. API was performed with curcumin $(80,100,120 \mu \mathrm{M})$ and LED light. Additional acrylic samples were treated with curcumin or LED light only. Positive control samples received neither light nor curcumin. After API, colony counts were quantified $(\mathrm{CFU} / \mathrm{mL})$, cell metabolism was determined by means of XTT assay, and the total biofilm biomass was evaluated using Crystal Violet (CV) staining assay and images were obtained by confocal laser scanning microscopy (CLSM). The data were analyzed by nonparametric two-way ANOVA and post hoc Tukey tests $(\alpha<0.05)$. For 24-h biofilm, API resulted in statistically significant difference $(\rho<0.001)$ of viability of C. albicans compared with control $(\mathrm{P}-\mathrm{L}-)$ for all Cur concentrations. For 48-h biofilm, API resulted in statistically significant difference $(\rho<0.001)$ compared with control only when Cur at $120 \mu \mathrm{M}$ was used. API promoted statistically
\end{abstract}

Ana Cláudia Pavarina

pavarina@foar.unesp.br

1 Department of Dental Materials and Prosthodontics, Institute of Science and Technology, UNESP, Univ Estadual Paulista, São José dos Campos, School of Dentistry - Avenida Engenheiro Francisco José Longo 777, CEP 12245-000 São José dos Campos, SP, Brazil

2 Department of Dental Materials and Prosthodontics, Araraquara Dental School, UNESP, Univ Estadual Paulista, Rua Humaitá 1680, CEP 14801-903 Araraquara, SP, Brazil

3 Physics Institute of São Carlos, USP, University of São Paulo, Av. Trabalhador São-Carlense, 400, CEP 13566-590 São Carlos, SP, Brazil significant difference $(\rho \leq 0.001)$ in the viability of $S$. mutans and $C$. glabrata for all Cur concentrations in the two biofilm ages. In addition, API produced a statistically significant difference $(\rho<0.001)$ of metabolic activity and of total biomass $(\rho<0.001)$ of multispecies biofilms compared with control for all Cur concentrations. It can be concluded that both 24- and 48-h biofilms were susceptible to API mediated by Cur; however, 24-h biofilm was more sensitive than the 48-h biofilm.

Keywords Photodynamic inactivation $\cdot$ Multispecies biofilm $\cdot$ Fungi $\cdot$ Bacteria

\section{Introduction}

The disease most commonly found in the oral mucosa of patients wearing removable dental prostheses is denominated denture stomatitis (DS) $[1,2]$. The etiology of DS is considered multifactorial; however, infection by Candida spp., especially Candida albicans, is considered the main etiologic factor $[3,4]$. The species of the genus Candida are capable of adhering directly to the denture surface, or by means of a bacterial layer primarily formed on this surface $[1,5]$. The continuous denture wearing associated with inadequate cleaning promotes conditions favorable to the proliferation of microorganisms [6]. Baena-Monroy et al. [7] demonstrated high prevalence of the microorganisms C. albicans, Streptococcus mutans, and Staphylococcus aureus (66.7, 49.5, and 49.5.4 \%, respectively) on surface of complete dentures. In a previous study, it was observed that Candida spp. were the most predominant microorganism $(60.0 \%)$ on dentures, followed by mutans Streptococci $(53.3 \%)$ and Staphylococcus spp. (48.3\%). Among the dentures positive for Candida spp., three species were identified: $C$. albicans was the 
most frequent yeast, followed by Candida glabrata and Candida tropicalis, respectively [8].

The biofilm adhered to the surface of dentures is characterized as being a complex microbial community, surrounded by a polymeric matrix, favoring the proliferation and survival of these microorganisms [9-12]. Innumerable mechanisms contribute to these microorganisms organized in biofilm presenting greater resistance to antimicrobial agents and being protected from the action of the host immunologic system $[13,14]$. Different treatments have been considered for DS, involving the prescription of topical and systemic antifungal medications and procedures for cleaning and disinfection of the dentures [15-17]. However, a high rate of recurrence of the infection has been observed [17-19]. The use of azole substances associated with failures in the therapeutic procedures may culminate in the resistance of microorganism to these drugs, which contributes to the failure of conventional therapies [20-22].

Due to the difficulties found in the treatment of oral infections using conventional treatments, antimicrobial photodynamic inactivation (API) has been used as an alternative for the inactivation of microorganisms. The photodynamic therapy has been used for more than 100 years for inactivating microorganisms, when Oscar Raab described for the first time the lethal effect of acridine hydrochloride and visible light on Paramecia caudatum. The photodynamic process requires the use of a chemical compound-denominated photosensitizer (PS), with the subsequent application of a light that corresponds to the absorption band of the PS in the presence of oxygen [23]. The interaction of the light with the PS results in oxygen reactive species capable of inducing inactivation of microbial cells [24-26]. In vitro studies have been demonstrated that photodynamic therapy is effective in killing Candida spp. in planktonic cultures [27-34] and reducing biofilm $[35,36]$ formation using methylene blue $[29,30,32-34$, $37,38]$, toluidine blue $\mathrm{O}[32,34,36,39]$, photofrin [35], tionin [34], porphyrins [28], phthalocyanine [31, 34], and malachite green [32]. In general, the studies that have evaluated API have related that their greatest efficacy occurs when the microorganism is presented in the planktonic form, promoting their complete photoinactivation $[26,40]$. Nevertheless, when microorganisms are organized in biofilm, only reduction in the number of microorganisms has been observed and the complete elimination was not achieved [26, 40-43]. According to Ramage et al. [12], there is a linear relationship between the increase in cell density, resulting from the time for the development of the biofilm, and the increase in its metabolic activity. These authors have also observed an increase in the resistance of mature biofilms to conventional antifungal treatment when compared with planktonic cultures. However, studies evaluating the efficacy of API considering different times of biofilm formation were not found.
Another factor that may influence the efficacy of API is the interaction between the different species. Pereira et al. [44] observed that photoactivation mediated by methylene blue and laser light of biofilms formed by C. albicans, S. aureus, and $S$. mutans was greater in single-species biofilms (2.32 to $3.29 \log _{10}$ of reduction) when compared with multispecies biofilms (1.00 to $2.44 \log _{10}$ of reduction). Quishida et al. [43], using different concentrations of Photodithazine ${ }^{\circledR}$ associated with LED light, observed greater bacterial inactivation compared with the fungal species of multispecies biofilms of S. mutans, C. albicans, and Candida glabrata.

Different PS have been employed for API, among them curcumin (diferuloylmethane, Cur), an extract from the rhizome of the plant Curcuma longa L. [45]. Various studies have suggested that Cur has anti-inflammatory, anticarcinogenic, immunomodulatory, and antimicrobial effects [46-48], which may be exacerbated by means of illuminating it at an adequate wavelength [49-51]. Dovigo et al. [41] demonstrated that the association between Cur at the concentration of $20 \mu \mathrm{M}$ and light dose of $5.28 \mathrm{~J} / \mathrm{cm}^{2}$ promoted complete inactivation of a planktonic suspension of $C$. albicans. However, for reducing the cell metabolism of the fungal biofilm, it was necessary to have a higher concentration of Cur $(40 \mu \mathrm{M})$ with the same light dose, demonstrating lower susceptibility of the biofilm to API (the metabolic activity of C. albicans, C. glabrata, and C. tropicalis biofilms was reduced by 85,85 , and $73 \%$, respectively, at $18 \mathrm{~J} / \mathrm{cm}^{-2}$ ). Pileggi et al. [52] verified that the PSs eosin-Y, rose bengal, and Cur in the concentrations of 5,1 , and $5 \mu \mathrm{M}$, respectively, were capable of significantly reducing $(\log \mathrm{CFU} / \mathrm{mL})$ the planktonic culture of Enterococcus faecalis after the application of blue light (from $7.8 \pm 0.70$ for Controls-no light to $2.9 \pm 0.30$ for Eosin $5 \mathrm{M}, 0.5 \pm 0.30$ for rose bengal $1 \mathrm{M}$ and $0.15 \pm 0.36$ for Cur). For bacterial biofilm, the concentrations of 100,10 , and $10 \mu \mathrm{M}$ of the PSs Eosin-Y, rose bengal, and Cur, respectively, resulted in complete suppression of the viability of E. faecalis. Araújo et al. [53] observed that the exposure of the biofilm to $0.75,1.5$, and $3.0 \mathrm{~g} / \mathrm{L}$ of Cur and subsequent illumination with light resulted in $97.5,95$, and $99.9 \%$ reductions in viable cells (respectively) in the multispecies biofilm of Streptococcus mutans and Lactobacillus acidophilus formed on dentin samples. When the Cur concentration was 4.0 and $5.0 \mathrm{~g} / \mathrm{L}$, a decrease of $100 \%$ was obtained.

Despite this, the investigation of the photodynamic ability of Cur against multispecies biofilm composed by bacteria and yeast of different ages could demonstrate better its antimicrobial potential for a further clinical evaluation. Besides, this kind of multispecies biofilm on acrylic resin should be investigated in order to mimic a biofilm found on dentures, where bacteria and yeasts are found. Therefore, the aim of this study 
was to evaluate the capacity of API mediated by the PS CUR for the inactivation of multispecies biofilm of $C$. albicans, C. glabrata, and S. mutans, formed on denture base acrylic resin for different periods of time.

\section{Material and methods}

\section{Preparation of acrylic resin samples}

The samples $(n=480)$ were fabricated from an acrylic denture base resin (Vipi Wave; VIPI Indústria e Comércio Exportação e Importação de Produtos Odontológicos Ltda, Pirassununga, SP, Brazil), in accordance with the manufacturer's specifications. The resin discs were fabricated using a metal mold with compartments $(10 \times 2 \mathrm{~mm})$. This metal mold was invested in the flask in dental stone sandwiched between two glass slabs that were sandblasted with aluminum oxide to obtain rough specimens with a roughness of approximately $3 \mu \mathrm{m}$ [54]. The acrylic resin polymerization cycle was performed in a $500-\mathrm{W}$ domestic microwave oven (Brastemp, Manaus, AM, Brazil) at $20 \%$ power for $20 \mathrm{~min}$, and subsequently at $90 \%$ power for $5 \mathrm{~min}$. The flasks were allowed to bench cool at room temperature; the specimens were deflasked, and excess flash was removed with a bur (Maxi-Cut; Lesfils de August Malleifer S.A., Ballaigues, Switzerland).

The surface roughness of all specimens was measured with a profilometer (Mitutoyo SJ 400, Mitutoyo Corporation, Japan). Four measurements were made for each specimen and the average reading was designated as the $\mathrm{Ra}(\mu \mathrm{m})$ value of the specimen. The resolution was $0.01 \mu \mathrm{m}$, interval (cutoff length) $0.8 \mathrm{~mm}$, transverse length $2.4 \mathrm{~mm}$, stylus speed $1 \mathrm{~mm} /$ $\mathrm{s}$, and the diamond stylus tip radius was $5 \mu \mathrm{m}$. Only specimens with surface roughness between 2.7 and $3.7 \mathrm{~mm}(\mathrm{Ra})$ were selected for the study, in order to simulate the internal surface of the denture [55]. After this, the samples were sterilized with ethylene oxide at the ACECIL (Central de Esterilização Com. Ind. Ltda, Campinas, SP) facilities.

\section{Biofilm production}

In this study, the microorganisms used to produce multispecies biofilm were C. albicans (ATCC 90028), Candida glabrata (ATCC 2001), and Streptococcus mutans (ATCC 25175) obtained from the American Type Culture Collection strains (ATCC; Rockville, MD, USA). C. albicans and C. glabrata were seeded on Sabouraud Dextrose Agar (SDA, Acumedia Manufacturers Inc., Baltimore, MD, USA) with $5 \mu \mathrm{g} / \mathrm{mL}$ of chloramphenicol and $S$. mutans on MitisSalivarius Agar (Difco, Laboratories, Detroit, MI, USA) supplemented with $15 \%$ sucrose and $0.2 \mathrm{IU} / \mathrm{mL}$ bacitracin (MSB plates), which were incubated at $37^{\circ} \mathrm{C}$ for $48 \mathrm{~h}$. To obtain the standardized suspension of each microorganism, the yeasts were individually inoculated in Yeast Nitrogen Base (YNB) medium supplemented with $100 \mathrm{mM}$ glucose and the bacteria were inoculated in Brain Heart Infusion (BHI, Himedia Laboratories, Mumbai, India). All microorganisms were incubated at $37{ }^{\circ} \mathrm{C}$ overnight under appropriate conditions. In all experiments, $S$. mutans was incubated in candle jar. Microbial cells were harvested, washed twice with phosphate-buffered saline (PBS, pH 7.2), and resuspended in BHI as previously described in the study of Quishida et al. [43]. After this, the microbial suspensions were spectrophotometrically standardized at concentration of $10^{7}$ cells $/ \mathrm{mL}$ for Candida species and $10^{8}$ cells $/ \mathrm{mL}$ for $S$. mutans, using wavelengths of 520 and $600 \mathrm{~nm}$, respectively [56]. Aliquots of $500 \mu \mathrm{L}$ of each standardized cell suspension were added to each well of a 24-well microtitler plate containing an acrylic resin specimen, which were incubated at $37^{\circ} \mathrm{C}$ in orbital shaker at $75 \mathrm{rpm}$ (adhesion phase) for $90 \mathrm{~min}$ [57]. The nonadherent cells were removed by washing samples twice with PBS. For biofilm formation, $2 \mathrm{~mL}$ of BHI medium was added in each well and the plates were incubated at $37^{\circ} \mathrm{C}$ in orbital shaker at $75 \mathrm{rpm}$ for a period of 24 or $48 \mathrm{~h}$. The negative control groups consisted of BHI medium without microorganisms. Experiments were repeated three times with individual samples in triplicate.

\section{API}

The Cur used as photosensitizer (PS) to sensitize the microbial biofilm was obtained from Sigma-Aldrich (St. Louis, Missouri, USA). A stock solution of Cur $(800 \mu \mathrm{M})$ was obtained by dissolving it in dimethylsulfoxide (DMSO) at $10 \%$. Immediately before the experiment, this solution was diluted in physiological solution $(0.85 \% \mathrm{NaCl})$ to the final concentrations of 80,100 , and $120 \mu \mathrm{M}$. The $10 \%$ concentration of DMSO was maintained in the final solutions, and it was selected on the basis of a previous study that had shown that it had no effect on Candida viability and no influence on API results [41]. In addition, histological analysis also revealed that this solution had no adverse effects on the tissue of mice when it was applied topically [58]. Cur was exposed to lightemitting diode (LEDs, LXHL-PR09, Luxeon ${ }^{\circledR}$ III emitter, Lumileds Lighting, San Jose, CA) in the blue region, and with emission from 440 to $460 \mathrm{~nm}$, the intensity of light emitted was $22 \mathrm{~mW} / \mathrm{cm}^{2}$ and fluence was $37.5 \mathrm{~J} / \mathrm{cm}^{2}$.

API was performed by the administration of Cur and exposure to $37.5 \mathrm{~J} / \mathrm{cm}^{2}$ of LED light ( $\mathrm{P}+\mathrm{L}+$ group). After biofilm formation ( 24 or $48 \mathrm{~h}$ ), the samples were washed twice with PBS, and according to the experimental groups described, $2 \mathrm{~mL}$ of Cur was added to groups $\mathrm{P}+\mathrm{L}+(24 \mathrm{~h})$, $\mathrm{P}+\mathrm{L}-(24 \mathrm{~h}), \mathrm{P}+\mathrm{L}+(48 \mathrm{~h})$, and $\mathrm{P}+\mathrm{L}-(48 \mathrm{~h})$, while $2 \mathrm{~mL}$ of physiological solution was added to groups $\mathrm{P}-\mathrm{L}+$ (24 h), P-L+ (48 h), P-L- (24 h), and P-L- (48 h). Next, the plates were incubated in the dark for $20 \mathrm{~min}$ (pre-irradiation time) [41]. After this period, the groups 
$\mathrm{P}+\mathrm{L}+(24 \mathrm{~h}), \mathrm{P}+\mathrm{L}+(48 \mathrm{~h}), \mathrm{P}-\mathrm{L}+(24 \mathrm{~h})$, and $\mathrm{P}-\mathrm{L}+(48 \mathrm{~h})$ were exposed to LED light, illuminating samples for $29 \min \left(37.5 \mathrm{~J} / \mathrm{cm}^{2}\right)$. Additional samples were treated either with $\mathrm{Cur}(\mathrm{P}+\mathrm{L}-)$ or LED light $(\mathrm{P}-\mathrm{L}+)$ only. Untreated control samples received neither light nor Cur $(\mathrm{P}-\mathrm{L}-)$.

After the samples had been submitted to the experimental conditions, the following biofilm viability evaluations were performed:

\section{Quantification of colonies}

Each specimen was individually placed in a centrifuge tube containing $4.5 \mathrm{~mL}$ of sterile physiological solution, and these tubes were vortexed for $1 \mathrm{~min}$ to detach the biofilms from the acrylic samples [59]. After this, aliquots of $25 \mu \mathrm{L}$ of serial dilutions $\left(10^{-1}, 10^{-2}, 10^{-3}\right.$, and $\left.10^{-4}\right)$ were seeded in duplicate on CHROMagar Candida (Difco, Laboratories, Detroit, MI, USA) and MSB (Mitis Salivarius Agar supplemented with $15 \%$ of sucrose and $0.2 \mathrm{IU} / \mathrm{mL}$ bacitracin) for the identification of Candida spp. and S. mutans, respectively. Green and pink colonies grown on CHROMAgar Candida were presumptively identified as $C$. albicans and C. glabrata, respectively. After incubation at $37{ }^{\circ} \mathrm{C}$ for $48 \mathrm{~h}$, the colony-forming unit per milliliter $(\mathrm{CFU} / \mathrm{mL})$ was determined and $\log$ transformed $\left(\log _{10}\right)$.

\section{Metabolic activity (XTT reduction assay)}

The effect of API on the metabolic activity of the multispecies biofilms was measured by XTT reduction assay. After treatments, acrylic samples with biofilms were transferred to another plate with wells containing $2 \mathrm{~mL}$ of XTT solution \{containing $1580 \mu \mathrm{L}$ PBS with $200 \mathrm{mM}$ glucose, $400 \mu \mathrm{L}$ XTT 2,3-bis(2-methoxy-4-nitro-5sulfophenyl)-5-[(phenylamino)carbonyl $]-2 \mathrm{H}$-tetrazolium hydroxide, and $20 \mu \mathrm{L}$ menadione $\}$. The plates were incubated in the dark at $37{ }^{\circ} \mathrm{C}$ for $3 \mathrm{~h}$. After this, $200 \mu \mathrm{L}$ of the solution was transferred to a 96-well microtitler plate and colorimetric measurement was read at $492 \mathrm{~nm}$ by means of a spectrophotometer (Thermo Plate-TP Reader) [60].

\section{Total biomass quantification}

Crystal Violet (CV) staining was performed for the quantification of total biomass. Acrylic samples were washed with PBS and then fixed with $2 \mathrm{~mL}$ of methanol for 15 min. Acrylic samples with fixed biofilms were removed, transferred to another plate, and allowed to dry at room temperature. After drying, $2 \mathrm{~mL}$ of $\mathrm{CV}(1 \%$, $v / v)$ was added to the wells and incubated for $5 \mathrm{~min}$.
Acrylic samples were washed with PBS and transferred to another plate with $2 \mathrm{~mL}$ of acetic acid $(33 \%, v / v)$ in each well in order to dissolve the stain. After this period, an aliquot of $200 \mu \mathrm{L}$ was transferred to a 96-well microtitler plate and the absorbance of the final solution was read at $570 \mathrm{~nm}$ by means of a spectrophotometer (Thermo Plate-TP Reader) [61].

\section{CLSM}

The confocal laser scanning microscopy (CLSM) images were obtained of the groups $\mathrm{P}+\mathrm{L}+(24 \mathrm{~h})$ and $\mathrm{P}+\mathrm{L}+(48 \mathrm{~h})$ with $120 \mu \mathrm{M}$ of curcumin because they showed greater microbial inactivation, and these groups were compared with the positive control groups $[\mathrm{P}-\mathrm{L}-(24 \mathrm{~h})$ and $\mathrm{P}-\mathrm{L}-(48 \mathrm{~h})]$. In addition, an image of the group $\mathrm{P}+\mathrm{L}-$ with $120 \mu \mathrm{M}$ of curcumin was obtained, because the presence of $120 \mu \mathrm{M}$ Cur, in the dark, promoted microbial reduction. After treatment, acrylic samples with biofilm were washed twice with PBS and stained with the Live/Dead BacLight viability kit containing SYTO-9 and Propidium Iodide (PI) (Molecular Probes, Inc., Eugene, OR, USA). Biofilms were stained in the dark and incubated at room temperature for $15 \mathrm{~min}$, according to the manufacturer's instructions. The maximum excitation/emission used for these stains was approximately $480 / 500 \mathrm{~nm}$ for SYTO-9 stain and 490/635 nm for PI [43]. Images were obtained with a Leica TCS SPE confocal microscope (Leica Microsystems GmbH, Wetzlar, Germany).

\section{Statistical analysis}

All experiments were conducted using three specimens on three independent occasions. $\mathrm{CFU} / \mathrm{mL}$ values were $\log$ transformed $\left(\log _{10}\right)$. Since the assumptions of normality and homoscedasticity were not always met, a nonparametric two-way ANOVA (using the groups of treatment and biofilm age as independent factors) followed by the Tukey test for multiple comparisons was used to analyze the data [ranks of $\log _{10}(\mathrm{CFU} / \mathrm{mL})$ and absorbance values]. The significance level was 0.05 , and SPSS software (IBM SPSS $^{\circledR}$ Statistics, version 20, Chicago, IL) was used.

\section{Results}

\section{Quantification of colonies}

For $C$. albicans, ANOVA on ranks showed that biofilm age was not a significant factor $(\rho=0.472$ ), while groups of treatment and the interaction between biofilm age and groups of treatment were significant factors $(\rho<0.001)$. When biofilms were cultivated for $24 \mathrm{~h}$, API $(\mathrm{P}+\mathrm{L}+)$ resulted in significant difference $(\rho<0.001)$ compared with control $(\mathrm{P}-\mathrm{L}-)$ for all 
Cur concentrations, which showed no significant difference ( $\rho \geq 0.998)$ among them. The application of light only did not affect the viability of $C$. albicans $(\rho=1.000)$, but treatment with Cur alone at 100 and $120 \mu \mathrm{M}$ demonstrated significant difference $(\rho \leq 0.001)$ compared with control $(\mathrm{P}-\mathrm{L}-)$. For 48-h biofilm, API $(\mathrm{P}+\mathrm{L}+)$ resulted in significant difference $(\rho<0.001)$ compared with control $(\mathrm{P}-\mathrm{L}-)$ only when Cur at $120 \mu \mathrm{M}$ was used. Application of light alone (P-L+) and Cur alone $(\mathrm{P}+\mathrm{L}-)$ at all concentrations evaluated, and API with Cur at 80 and $100 \mu \mathrm{M}$ did not show significant difference $(\rho \geq 0.989)$. API with Cur at $120 \mu \mathrm{M}$ showed no significant difference $(P=1.000)$ between the two biofilm ages ( 24 and 48 h) (Fig. 1).

For $C$. glabrata, ANOVA on ranks demonstrated significant effects of biofilm age $(P<0.001)$, groups of treatment $(P<0.001)$, and the interaction between these factors $(\rho=0.038)$. API $(\mathrm{P}+\mathrm{L}+)$ mediated by $\mathrm{Cur}$ at all concentrations evaluated resulted in significant difference $(\rho<0.001)$ compared with control $(\mathrm{P}-\mathrm{L}-)$ for the two biofilm ages ( 24 and $48 \mathrm{~h}$ ). Concentrations of Cur showed no significant difference $(\rho \geq 0.999)$ among API $(\mathrm{P}+\mathrm{L}+)$ groups for the two biofilm ages. When biofilms (24 and $48 \mathrm{~h}$ ) were treated with light only $(\mathrm{P}-\mathrm{L}+)$ or Cur only $(\mathrm{P}+\mathrm{L}-)$, no significant difference $(\rho \geq 0.085)$ was found compared with control $(\mathrm{P}-\mathrm{L}-)$ and among them, except for Cur only at $120 \mu \mathrm{M}$, which showed significant difference compared with control $(\rho=0.001)$ and light only ( $\rho=0.004)$ for $24-\mathrm{h}$ biofilm. Controls ( $\mathrm{P}-\mathrm{L}-$ ) of the two biofilm ages (24 and $48 \mathrm{~h}$ ) showed no significant difference between them $(\rho=0.999)$, nor did the API groups $(\mathrm{P}+\mathrm{L}+)$ of the two biofilm ages $(\rho \geq 0.128)$ (Fig. 2).

For S. mutans, ANOVA on ranks also showed significant effect for biofilm age $(\rho=0.001)$, groups of treatment $(\rho<0.001)$, and the interaction between them $(\rho<0.001)$. API resulted in significant difference $(\rho \leq 0.001)$ for all Cur concentrations in the two biofilm ages. No significant difference ( $\rho \geq 0.055)$ was observed for $\mathrm{P}-\mathrm{L}-$ (controls), $\mathrm{P}$ $-\mathrm{L}+$, and $\mathrm{P}+\mathrm{L}-$ groups for all Cur concentrations in the two biofilm ages, except for $\mathrm{P}+\mathrm{L}-$ group with Cur $120 \mu \mathrm{M}$, which showed significant difference compared with control ( $\mathrm{P}-\mathrm{L}-$, $\rho=0.010)$ and $\mathrm{P}-\mathrm{L}+(\rho=0.002)$ for $24-\mathrm{h}$ biofilm. For the two biofilm ages (24 and $48 \mathrm{~h})$, no significant difference $(\rho=1.000)$ was verified among API $(\mathrm{P}+\mathrm{L}+)$ groups when Cur concentrations were compared. Control $(\mathrm{P}-\mathrm{L}-)$ groups of the two biofilm ages showed no significant $(\rho=1.000)$ difference between them, nor did the API groups $(\mathrm{P}+\mathrm{L}+)$ of the two biofilm ages ( $\rho \geq 0.942)$ (Fig. 3).

\section{Metabolic activity (XTT reduction assay)}

ANOVA on ranks demonstrated a significant effect of biofilm age $(\rho<0.001)$, groups of treatment $(\rho<0.001)$, and the interaction between them $(\rho=0.026)$. For 24 -h biofilm, a significant difference $(\rho<0.001)$ of absorbance values was verified when API groups $(\mathrm{P}+\mathrm{L}+)$ with all Cur concentrations were compared with control $(\mathrm{P}-\mathrm{L}-)$. No significant difference ( $\rho \geq 0.102)$ was observed among control $(\mathrm{P}-\mathrm{L}-$ ), samples

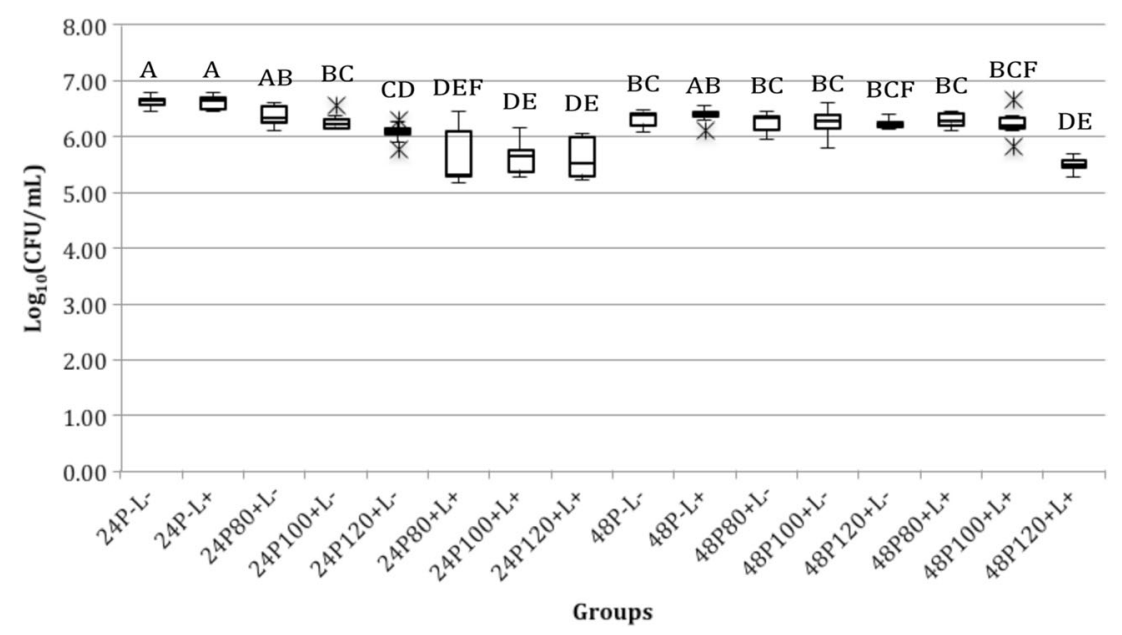

Fig. 1 Summary of $\log _{10} \mathrm{CFU} / \mathrm{mL}$ values of $C$. albicans. Box plots show the median (dash), first and third quartiles (box), highest and lowest values (error bars), and outliers (asterisk). 24P- $\mathrm{L}-$ : control group of 24-h multispecies biofilm. 24P-L+: 24-h multispecies biofilm treated with light only $\left(37.5 \mathrm{~J} / \mathrm{cm}^{2}\right)$. 24P80+L-: $24-\mathrm{h}$ multispecies biofilm treated with Cur only at $80 \mu \mathrm{M}$. $24 \mathrm{P} 100+\mathrm{L}-:$ : $24-\mathrm{h}$ multispecies biofilm treated with Cur only at $100 \mu \mathrm{M}$. 24P120+L-: 24-h multispecies biofilm treated with Cur only at $120 \mu \mathrm{M}$. 24P80+L+: 24-h multispecies biofilm submitted to API with Cur at $80 \mu \mathrm{M}$. 24P100+L+: 24-h multispecies biofilm submitted to API with Cur at $100 \mu \mathrm{M}$. 24P120+L+: 24-h multispecies biofilm submitted to API with Cur at $120 \mu \mathrm{M}$. 48P-L-: control group of 48-h multispecies biofilm. 48P-L+: 48-h multispecies biofilm treated with light only $\left(37.5 \mathrm{~J} / \mathrm{cm}^{2}\right)$. $48 \mathrm{P} 80+\mathrm{L}-: 48$-h multispecies biofilm treated with Cur only at $80 \mu \mathrm{M}$. $48 \mathrm{P} 100+\mathrm{L}-$ : 48 -h multispecies biofilm treated with Cur only at $100 \mu \mathrm{M} .48 \mathrm{P} 120+\mathrm{L}-:$ : 48-h multispecies biofilm treated with Cur only at $120 \mu \mathrm{M}$. 48P80+L+: 48-h multispecies biofilm submitted to API with Cur at $80 \mu \mathrm{M}$. 48P100+L+: $48-\mathrm{h}$ multispecies biofilm submitted to API with Cur at $100 \mu \mathrm{M}$. 48P120+ L+: 48-h multispecies biofilm submitted to API with Cur at $120 \mu \mathrm{M}$. Different letters denote significant difference $(P<0.05)$ according to the post hoc test 


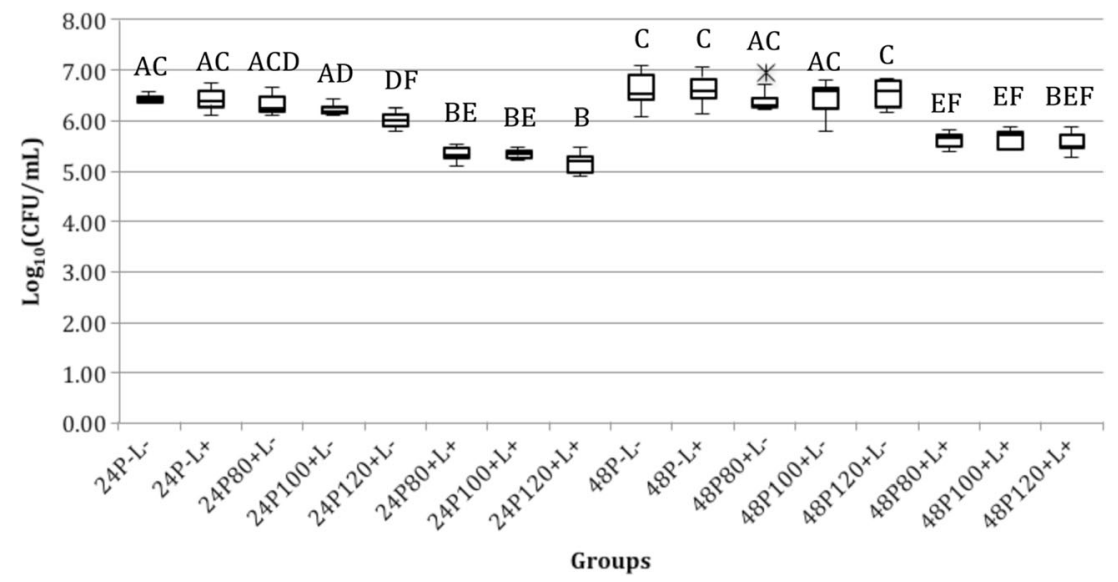

Fig. 2 Summary of $\log _{10} \mathrm{CFU} / \mathrm{mL}$ values of $C$. glabrata. Box plots show the median (dash), first and third quartiles (box), highest and lowest values (error bars), and outliers (asterisk). 24P- $\mathrm{L}-$ : control group of 24-h multispecies biofilm. 24P-L+: 24-h multispecies biofilm treated with light only $\left(37.5 \mathrm{~J} / \mathrm{cm}^{2}\right)$. 24P80+L-: 24 -h multispecies biofilm treated with Cur only at $80 \mu \mathrm{M}$. 24P100+L-: 24-h multispecies biofilm treated with Cur only at $100 \mu \mathrm{M} .24 \mathrm{P} 120+\mathrm{L}-$ : 24-h multispecies biofilm treated with Cur only at $120 \mu \mathrm{M}$. 24P80+L+: 24-h multispecies biofilm submitted to API with Cur at $80 \mu \mathrm{M}$. 24P100+L+: 24-h multispecies biofilm submitted to API with Cur at $100 \mu \mathrm{M}$. 24P120+L+: 24-h multispecies biofilm submitted to API with Cur at $120 \mu \mathrm{M}$. $48 \mathrm{P}-\mathrm{L}-$ :

treated only by light $(\mathrm{P}-\mathrm{L}+)$, and those treated only by Cur $(\mathrm{P}+\mathrm{L}-)$ for all concentrations. When 48 -h biofilm was evaluated, API $(\mathrm{P}+\mathrm{L}+)$ also resulted in a significant difference $(\rho<0.001)$ compared with control $(\mathrm{P}-\mathrm{L}-)$ for all Cur concentrations. No significant difference $(\rho \geq 0.992)$ was observed when control $(\mathrm{P}-\mathrm{L}-), \mathrm{P}-\mathrm{L}+$, and $\mathrm{P}+\mathrm{L}-$ groups were compared for all Cur concentrations. For the two biofilm ages (24 and $48 \mathrm{~h}$ ), no significant difference $(\rho \geq 0.996)$ was verified among API $(\mathrm{P}+\mathrm{L}+)$ groups when Cur concentrations were compared. Furthermore, absorbance values of 24-h biofilm were significantly different than those of the 48-h biofilm when controls $\left(\mathrm{P}-\mathrm{L}^{-}\right)$were compared $(\rho<0.001)$ (Fig. 4).

\section{Total biomass quantification}

ANOVA on ranks demonstrated a significant effect for biofilm age $(\rho<0.001)$ and groups of treatment $(\rho<0.001)$ but not for the interaction between them $(\rho=0.836)$. API $(\mathrm{P}+\mathrm{L}+)$ resulted in significant difference $(\rho<0.001)$ compared with control $(\mathrm{P}-\mathrm{L}-)$ for all Cur concentrations, which showed no significant difference among them $(\rho \geq 0.331)$. No significant difference $(\rho \geq 0.233)$ was verified among control ( $\mathrm{P}-\mathrm{L}-)$, $\mathrm{P}-\mathrm{L}+$, and $\mathrm{P}-\mathrm{L}+$ groups for all Cur concentrations (Fig. 5).

\section{Biofilm analysis by CLSM}

The images obtained by CLSM (Figs. 6 and 7) show that after the applications of API mediated by Cur at $120 \mu \mathrm{M}[\mathrm{P}+\mathrm{L}+$ control group of 48-h multispecies biofilm. 48P-L+: 48-h multispecies biofilm treated with light only $\left(37.5 \mathrm{~J} / \mathrm{cm}^{2}\right) .48 \mathrm{P} 80+\mathrm{L}-: 48$-h multispecies biofilm treated with Cur only at $80 \mu \mathrm{M}$. $48 \mathrm{P} 100+\mathrm{L}-: 48-\mathrm{h}$ multispecies biofilm treated with Cur only at $100 \mu \mathrm{M} .48 \mathrm{P} 120+\mathrm{L}-$ : $48-\mathrm{h}$ multispecies biofilm treated with Cur only at $120 \mu \mathrm{M}$. 48P80+L+: 48 -h multispecies biofilm submitted to API with Cur at $80 \mu \mathrm{M}$. 48P100+L+: $48-\mathrm{h}$ multispecies biofilm submitted to API with Cur at $100 \mu \mathrm{M}$. 48P120+ L+: 48-h multispecies biofilm submitted to API with Cur at $120 \mu \mathrm{M}$. Different letters denote significant difference $(P<0.05)$ according to the post hoc test

(24 h) and $\mathrm{P}+\mathrm{L}+(48 \mathrm{~h})]$ (Figs. 6e and $7 \mathrm{c})$ on multispecies biofilm formed on the resin test specimens in 24 and $48 \mathrm{~h}$, there was a visible increase in the number of cells marked with red fluorescence, indicating microbial cell damage, when compared with their respective controls $\mathrm{P}-\mathrm{L}-(24 \mathrm{~h})$ and $\mathrm{P}$ $-\mathrm{L}-(48 \mathrm{~h})$ (Figs. 6a and 7a). Furthermore, in group $\mathrm{P}+\mathrm{L}-$ (24 h) with Cur at $120 \mu \mathrm{M}$, presented in Fig. $4 \mathrm{c}$, a visible increase in the cells with red fluorescence was observed when compared with group $\mathrm{P}-\mathrm{L}-(24 \mathrm{~h})$ (Fig. 6a). The cross section of biofilms showed thickness of $20,19,17,23.5$, and $22 \mu \mathrm{m}$, with reference to groups $\mathrm{P}-\mathrm{L}-(24 \mathrm{~h}), \mathrm{P}+\mathrm{L}-(24 \mathrm{~h}), \mathrm{P}+\mathrm{L}+$ $(24 \mathrm{~h}), \mathrm{P}-\mathrm{L}-(48 \mathrm{~h})$, and $\mathrm{P}+\mathrm{L}+(48 \mathrm{~h})$, respectively (Figs. 6b, $d, f$ and $7 b, d$ ).

\section{Discussion}

The results of this study demonstrated that the application of API was a significant factor in all the assessment performed (quantification of colonies, metabolic activity, and total biomass) in multispecies biofilm, as well as for biofilm age (24 and $48 \mathrm{~h}$ ), which was not significant only for C. albicans. Thus, for all the evaluations performed, the results obtained for the $48 \mathrm{~h}$ biofilm differed significantly from those of 24-h biofilm except for the quantification of $C$. albicans colonies. Moreover, the interaction of these factors (biofilm age and groups of treatment) was also significant for all the evaluations performed, except for biofilm biomass. By means of colony quantification, it was verified that API significantly 


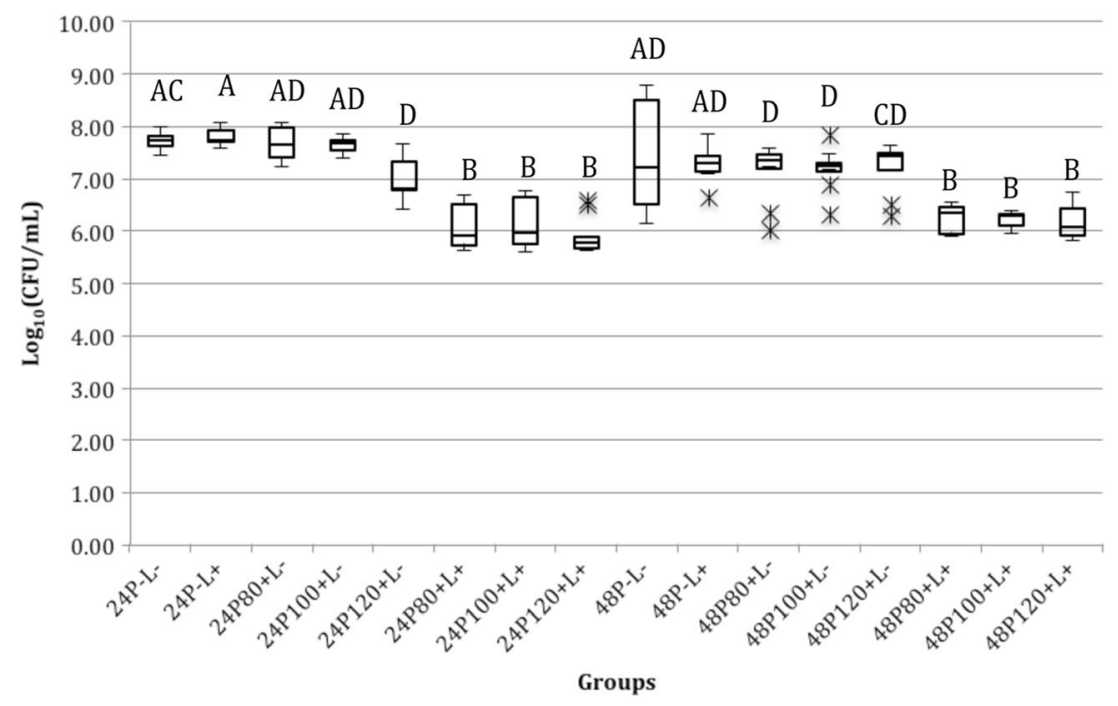

Fig. 3 Summary of $\log _{10} \mathrm{CFU} / \mathrm{mL}$ values of $S$. mutans. Box plots show the median (dash), first and third quartiles (box), highest and lowest values (error bars), and outliers (asterisk). 24P-L-: control group of 24-h multispecies biofilm. 24P-L+: 24-h multispecies biofilm treated with light only $\left(37.5 \mathrm{~J} / \mathrm{cm}^{2}\right)$. 24P80+L-: $24-\mathrm{h}$ multispecies biofilm treated with Cur only at $80 \mu \mathrm{M}$. 24P100+L-: 24-h multispecies biofilm treated with Cur only at $100 \mu \mathrm{M}$. 24P120+L-: 24-h multispecies biofilm treated with Cur only at $120 \mu \mathrm{M}$. 24P80+L+: 24-h multispecies biofilm submitted to API with Cur at $80 \mu \mathrm{M}$. 24P100+L+: 24-h multispecies biofilm submitted to API with Cur at $100 \mu \mathrm{M}$. 24P120+L+: 24-h multispecies biofilm submitted to API with Cur at $120 \mu \mathrm{M}$. 48P-L-: control group of 48-h multispecies biofilm. 48P-L+: 48-h multispecies biofilm treated with light only $\left(37.5 \mathrm{~J} / \mathrm{cm}^{2}\right) .48 \mathrm{P} 80+\mathrm{L}-: 48$-h multispecies biofilm treated with Cur only at $80 \mu \mathrm{M}$. $48 \mathrm{P} 100+\mathrm{L}-$ : 48 -h multispecies biofilm treated with Cur only at $100 \mu \mathrm{M} .48 \mathrm{P} 120+\mathrm{L}-:$ : 48-h multispecies biofilm treated with Cur only at $120 \mu \mathrm{M}$. 48P80+L+: 48-h multispecies biofilm submitted to API with Cur at $80 \mu \mathrm{M}$. 48P100+L+: $48-\mathrm{h}$ multispecies biofilm submitted to API with Cur at $100 \mu \mathrm{M}$. 48P120+ L+: 48-h multispecies biofilm submitted to API with Cur at $120 \mu \mathrm{M}$. Different letters denote significant difference $(P<0.05)$ according to the post hoc test

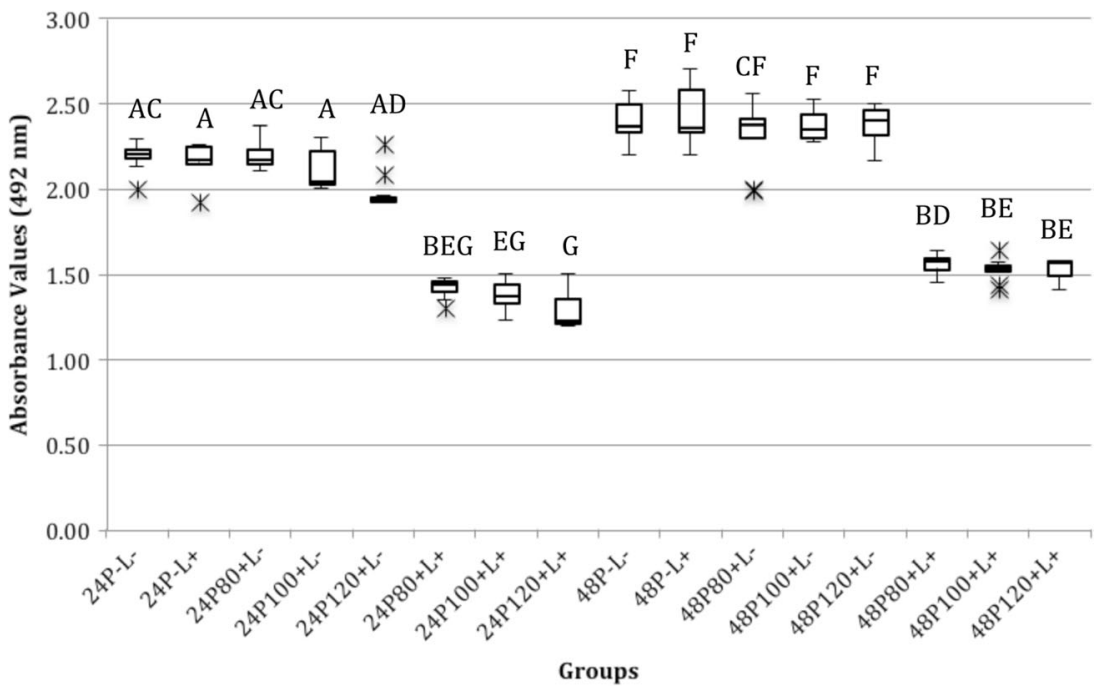

Fig. 4 Summary of metabolic activity of multispecies biofilm. Box plots show the median (dash), first and third quartiles (box), highest and lowest values (error bars), and outliers (asterisk). 24P- $\mathrm{L}-$ : control group of $24-\mathrm{h}$ multispecies biofilm. 24P-L+: 24-h multispecies biofilm treated with light only $\left(37.5 \mathrm{~J} / \mathrm{cm}^{2}\right) .24 \mathrm{P} 80+\mathrm{L}-: 24-\mathrm{h}$ multispecies biofilm treated with Cur only at $80 \mu \mathrm{M}$. $24 \mathrm{P} 100+\mathrm{L}-: 24-\mathrm{h}$ multispecies biofilm treated with Cur only at $100 \mu \mathrm{M}$. $24 \mathrm{P} 120+\mathrm{L}-: 24-\mathrm{h}$ multispecies biofilm treated with Cur only at $120 \mu \mathrm{M}$. 24P80+L+: 24-h multispecies biofilm submitted to API with Cur at $80 \mu \mathrm{M}$. 24P100+L+: 24-h multispecies biofilm submitted to API with Cur at $100 \mu \mathrm{M}$. 24P120+L+: 24-h multispecies biofilm submitted to API with Cur at $120 \mu \mathrm{M}$. 48P-L-: control group of 48-h multispecies biofilm. 48P-L+: 48-h multispecies biofilm treated with light only $\left(37.5 \mathrm{~J} / \mathrm{cm}^{2}\right) .48 \mathrm{P} 80+\mathrm{L}-: 48-\mathrm{h}$ multispecies biofilm treated with Cur only at $80 \mu \mathrm{M}$. $48 \mathrm{P} 100+\mathrm{L}-$ : 48 -h multispecies biofilm treated with Cur only at $100 \mu \mathrm{M} .48 \mathrm{P} 120+\mathrm{L}-:$ : 48-h multispecies biofilm treated with Cur only at $120 \mu \mathrm{M}$. 48P80+L+: 48-h multispecies biofilm submitted to API with Cur at $80 \mu \mathrm{M}$. $48 \mathrm{P} 100+\mathrm{L}+: 48-\mathrm{h}$ multispecies biofilm submitted to API with Cur at $100 \mu \mathrm{M}$. 48P120+ L+: 48-h multispecies biofilm submitted to API with Cur at $120 \mu \mathrm{M}$. Different letters denote significant difference $(P<0.05)$ according to the post hoc test 


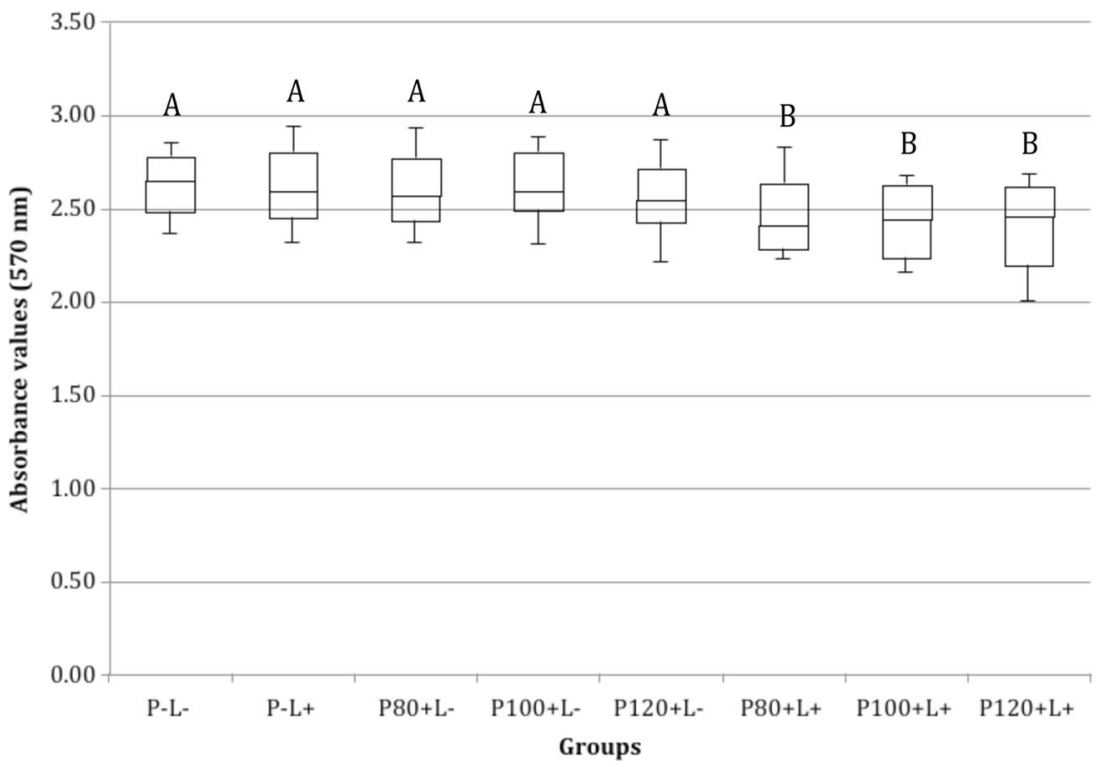

Fig. 5 Summary of total biomass of 24- and 48-h multispecies biofilms. Box plots show the median (dash), first and third quartiles (box), highest and lowest values (error bars), and outliers (asterisk). $\mathrm{P}-\mathrm{L}-$ : control group. $\mathrm{P}-\mathrm{L}+$ : biofilms treated with light only $\left(37.5 \mathrm{~J} / \mathrm{cm}^{2}\right)$. $\mathrm{P} 80+\mathrm{L}-$ : biofilms treated with Cur only at $80 \mu \mathrm{M}$. P100+L-: biofilms treated with Cur only at $100 \mu \mathrm{M}$. 24P120+L-: biofilms treated with Cur only at $120 \mu \mathrm{M}$. P80+L+: biofilms submitted to API with Cur at $80 \mu \mathrm{M}$ P100+L+: biofilm submitted to API with Cur at $100 \mu \mathrm{M}$. P120+L+: biofilms submitted to API with Cur at $120 \mu \mathrm{M}$. Different letters denote significant difference $(P<0.05)$ according to the post hoc test for the factor groups of treatment

Therefore, the lower susceptibility of $C$. albicans to API in multispecies biofilms of $48 \mathrm{~h}$ may be justified by the phase of maturation being more resistant than the intermediate phase reached by the 24-h biofilm.

Since $\log _{10}$ reduction cannot be calculated due to nonparametric analysis of the data, the reduction of microbial species could be estimated as observed in data shown in the box plot figures. For C. albicans (Fig. 1), considering all samples shown in box plots, it is possible to observe for API groups (biofilm of 24 and $48 \mathrm{~h}$ ) a reduction near to $0.5 \log _{10}$ compared with all samples from the controls (biofilm of 24 and 48 h). For C. glabrata, Fig. 2 shows that samples of $24 \mathrm{~h}$ submitted to API demonstrated a reduction near to $1 \log _{10}$ compared with the control (biofilm of $24 \mathrm{~h}$ ). On the other hand, although a significant difference was also verified, the reduction for 48-h samples observed in the API group compared with control was near to $0.5 \log _{10}$. For $S$. mutans, samples of $24 \mathrm{~h}$ submitted to API showed a reduction near to 1.5 $\log _{10}$ compared with control as observed in Fig. 3. However, for $48 \mathrm{~h}$, although a significant difference was verified, Fig. 3 shows a high variation in the control group, which values are close to API group. Thus, a reduction could not be estimated. A previous study cultivated the 48-h biofilm with the same three species on polystyrene plate and found reductions from $1.19 \log _{10}$ to $2.39 \log _{10}$ after API mediated by Photodithazine (PDZ) [43]. Another study, using the same 48-h multispecies biofilm of the present investigation and PDZ as a photosensitizer, demonstrated no significant difference between samples submitted to API and untreated control when 1 and 3 API 
Fig. 6 CLSM image of multispecies biofilms grown on acrylic resin samples stained with fluorochromes SYTO-9 and PI. Red cells are considered death (PI) and green cells are considered live (SYTO-9). a Image of 24-h biofilm from the control group $(\mathrm{P}-\mathrm{L}-(24 \mathrm{~h}))$. b Cross sections and side views of $20 \mu \mathrm{m}$ (yellow line) thick biofilm from group $\mathrm{P}-\mathrm{L}-(24 \mathrm{~h})$. c Image of biofilm from group $\mathrm{P}+\mathrm{L}-$ $(120 \mu \mathrm{M}$ of Cur without LED light) $(\mathrm{P}+\mathrm{L}-(24 \mathrm{~h}))$. d Cross sections and side views of $19.0 \mu \mathrm{m}$ (yellow line) thick biofilm of group $\mathrm{P}+\mathrm{L}-(24 \mathrm{~h})$. e Image of 24-h biofilm after API $(\mathrm{P}+\mathrm{L}+(24 \mathrm{~h}))$. f Cross sections and side views of 17.0- $\mu \mathrm{m}$ (yellow line) thick biofilm from group $\mathrm{P}+\mathrm{L}+$ $(24 \mathrm{~h})$. White arrows show filamentous form of C. albicans (hyphae/ pseudohyphae)
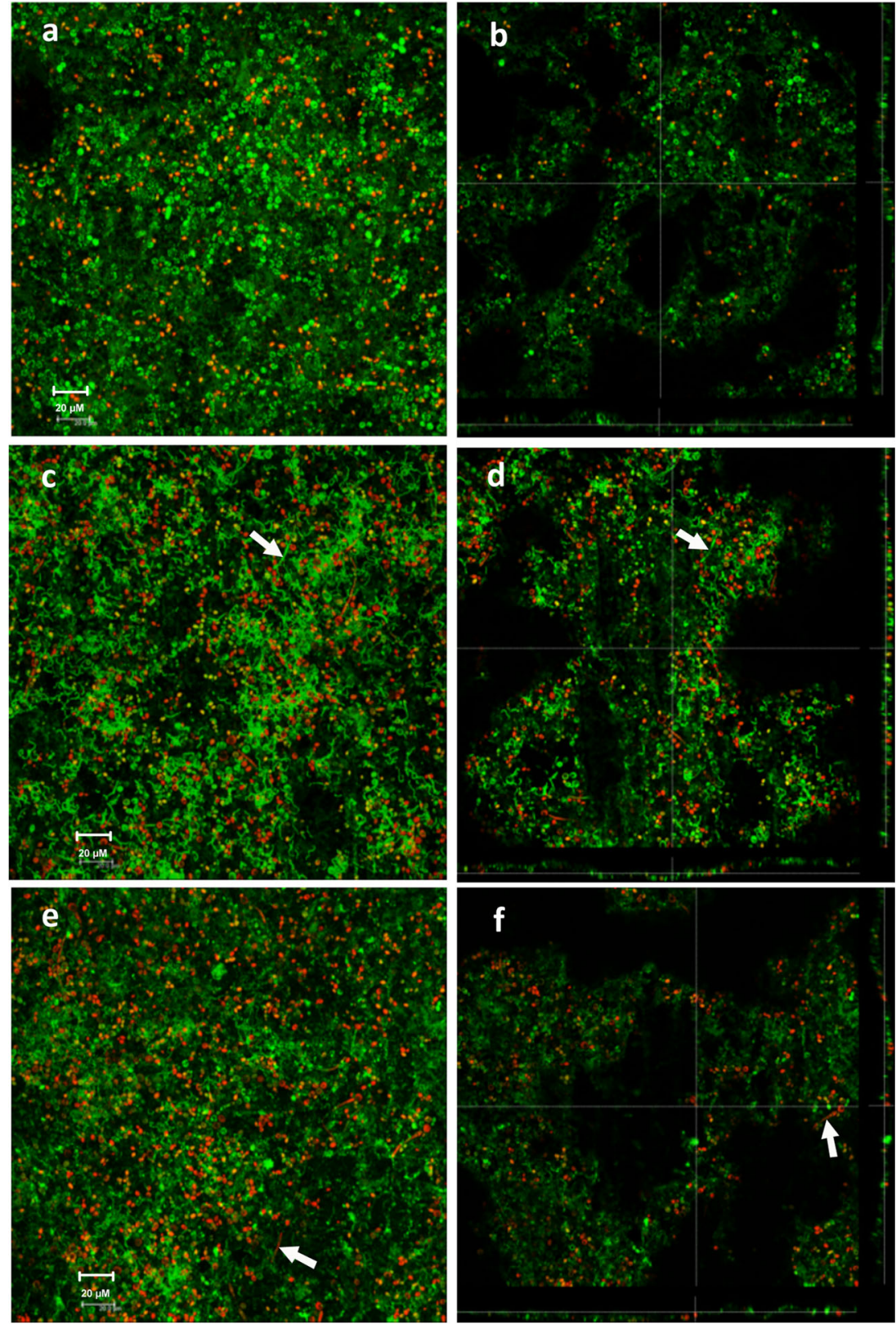

applications were performed [62]. Therefore, the results of the present investigation could be considered more relevant than this previous study. However, it is important to emphasize that the $\log _{10}$ reduction cannot be calculated in this investigation.

Furthermore, in the absence of LED light $(\mathrm{P}+\mathrm{L}-)$, it was verified that the higher concentration of Cur $(120 \mu \mathrm{M})$ promoted significant reduction in cell viability of the microorganisms in the 24-h biofilm and so did the concentration of $100 \mu \mathrm{M}$ in $C$. albicans. This result is in agreement with those of studies that have suggested that the application of Cur alone may present an antimicrobial effect [46-48, 63]. A study conducted by Garcia-Gomes et al. [63] confirmed the antifungal effect of Cur when verifying that the concentration of $50 \mu \mathrm{M}$ of Cur, in the absence of light, was capable of inhibiting the growth of C. albicans. Therefore, the association of Cur with light has been proposed to potentiate its antifungal action [41]. In the 48-h biofilm, the microorganisms C. glabrata and $S$. mutans presented a reduction in cell viability for the three concentrations of Cur when associated with LED light, whereas for $C$. albicans, the reduction in $\log _{10}(\mathrm{CFU} / \mathrm{mL})$ values was obtained only for the highest concentration used. According to the scanning electron microscopy and confocal microscopy images obtained by Seneviratne et al. [60], C. albicans forms thicker biofilms that present tridimensional characteristics and multiple layers of biofilm, when compared with that of 
Fig. 7 a CLSM image of 48-h biofilm from the control group $(\mathrm{P}-\mathrm{L}-(48 \mathrm{~h}))$. b Cross sections and side views of $23.5-\mu \mathrm{m}$ (yellow line) thick biofilm from group $\mathrm{P}-\mathrm{L}-(48 \mathrm{~h})$. c Image of 48-h biofilm from group $\mathrm{P}+\mathrm{L}+$ $(120 \mu \mathrm{M}$ of Cur and LED light). d Cross sections and side views of $22.0-\mu \mathrm{m}$ (yellow line) thick biofilm from group $\mathrm{P}+\mathrm{L}+(24 \mathrm{~h})$. White arrows show filamentous form of C. albicans (hyphae/ pseudohyphae)
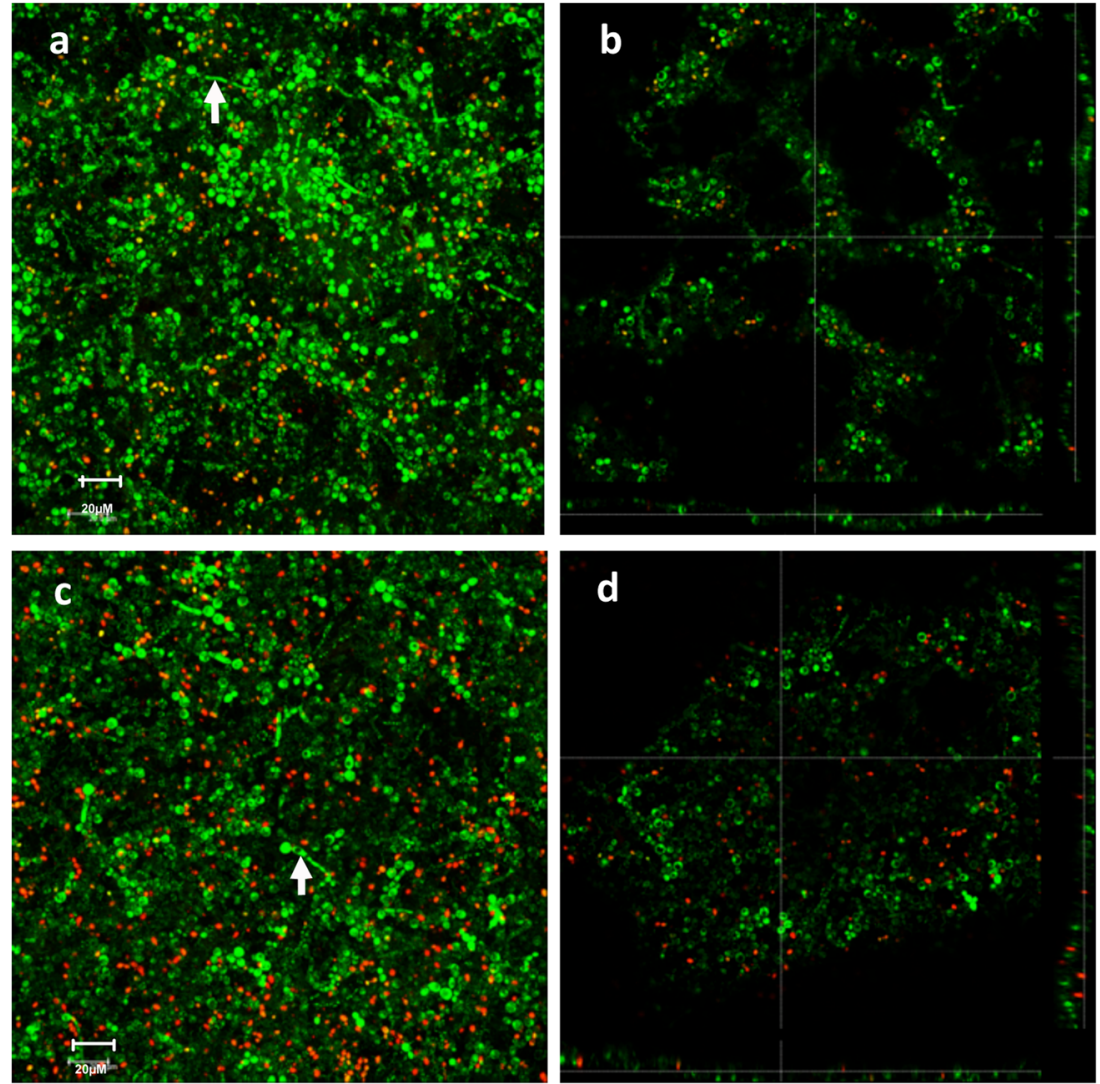

C. glablata, which produces thin, compact biofilms. Therefore, the more robust architecture of the biofilm formed by $C$. albicans may have been a relevant factor that made it difficult for the PS Cur to act on the biofilm. In addition, for the 48-h biofilm, differing from the 24-h biofilm, none of the concentrations of Cur in the absence of light $(\mathrm{P}+\mathrm{L}-$ with 80,100 , and $120 \mu \mathrm{M})$ was capable of reducing the cell viability of the microorganisms evaluated. Therefore, it may be suggested that the higher resistance of the 48-h biofilm made it difficult for API to act on the microorganisms.

Moreover, the different concentrations of Cur promoted no significant difference with regard to the effectiveness of API. In the study of Dovigo et al. [41], the photodegradation of Cur was evaluated, in which it was shown that for the concentration of $20 \mu \mathrm{M}$, light doses higher than $5.28 \mathrm{~J} / \mathrm{cm}^{2}$ did not promoted an increase in the effectiveness of API. This occurred because as from $4 \mathrm{~min}$ (time with reference to the dose of $5.28 \mathrm{~J} / \mathrm{cm}^{2}$ ), there was an increase in the photodegradation of Cur $(20 \mu \mathrm{M})$ and reduction in the production of reactive oxygen species, thus stabilizing the phototoxic effect of Cur. In the present study, much higher concentrations of Cur (80, 100 , and $120 \mu \mathrm{M}$ ) were used for API than those that were used in the study of Dovigo et al. [41]. However, no statistical difference between the concentrations used was verified.
This may have occurred because the light dose of $37.5 \mathrm{~J} / \mathrm{cm}^{2}$ had probably not been sufficient to completely activate all the molecules of the PS present in these more concentrated solutions, and therefore, a complete photodegradation of the PS may not have occurred, in addition to a restricted production of reactive oxygen species. The possibility of complete photodegradation not having occurred is due to the fact that during the experimental phase, no complete photowhitening of the Cur solutions was observed after illumination with LED. Thus, the limited production of reactive oxygen species may have attained a threshold of phototoxicity, and therefore, the higher concentrations were not more efficient for the reduction in cell viability when compared with the lower concentration. Taking into consideration the limitations of this study, higher light doses were not evaluated due to the long time interval of illumination necessary for these doses. The LED appliance available for the study has an intensity of $22 \mathrm{~mW} / \mathrm{cm}^{2}$, and to obtain a light dose of $37.5 \mathrm{~J} / \mathrm{cm}^{2}$, a period of $29 \mathrm{~min}$ of illumination was required. Therefore, longer times of illumination may make the application of the therapy clinically unfeasible. However, further studies are necessary, which evaluate different light doses for illuminating high concentrations of Cur, using more powerful appliances to diminish the time of illumination. 
The results of biofilm metabolic activity (XTT assay) showed that both 24-h and 48-h biofilm were susceptible to API, confirming the results obtained in the colony quantification assays. For the biofilms of both ages ( 24 and $48 \mathrm{~h}$ ), the three concentrations of Cur with light were capable of promoting a reduction in cell metabolism. Although no significant difference was observed among the three concentrations, the highest reduction was $40.62 \%$ for the group API $(\mathrm{P}+\mathrm{L}+)$ mediated by the concentration of $120 \mu \mathrm{M}$ of Cur. This result is in agreement with the findings of Quishida et al. [43], who also verified a significant reduction in metabolic activity of multispecies biofilm of C. albicans, C. glabrata, and S. mutans after API mediated by the PS Photodithazine for all the concentrations evaluated. Differently from the quantification of colonies, the presence of Cur at $120 \mu \mathrm{M}$ in the absence of light was not capable of reducing the cell metabolism for the younger biofilms $(24 \mathrm{~h})$. Although this result differs from that of $\mathrm{CFU} / \mathrm{mL}$, it suggests that the antimicrobial action of Cur alone is not as effective in reducing the cell metabolism as is its association with light. For the control group ( $\mathrm{P}-\mathrm{L}-)$, greater metabolic activity of the 48 -h biofilm was verified when compared with that of the 24-h biofilm, suggesting significantly greater viability of the more mature biofilm. In spite of this, as with the CFU/mL test, the action of API on 48-h biofilm did not differ from that of the 24-h biofilm, suggesting similar susceptibility of both biofilm ages to the photodynamic effects. This difference observed in the metabolic activity of the controls and API groups for the biofilms of different ages may be justified by the fact that the XTT assay was performed immediately after treatment of the biofilm so that there was no possibility of recovery of the cells affected by photodynamic action, producing similar absorbance values for the 24- and 48-h biofilms, differently to that observed for the control groups. Whereas for the quantification of colonies, during the period of $48 \mathrm{~h}$ of incubation for the growth of colonies, some cells may recover from phototoxic damages and become viable. Therefore, it is important to complement the viability tests performed. The advantages of the XTT assay are the rapidity of the test and the possibility of working with whole biofilm, without rupturing it.

The results of the violet crystal test demonstrated that the 48-h biofilm presented significantly higher biomass values in comparison with the 24-h biofilm, as expected, due to the maturity of the 48-h biofilm. Moreover, API mediated by the three concentrations of Cur reduced the total biomass of biofilm in comparison with the control $(\mathrm{P}-\mathrm{L}-)$. According to these results, API was not only capable of reducing the cell viability and cell metabolism but was also efficient for reducing the total biomass of biofilms formed on the acrylic resin test specimens. This result is in agreement with those obtained by Dovigo et al. [26], with monospecies biofilms from clinical isolates of Candida spp., which presented reduction in biomass from 52.3 to $64.1 \%$ after photoinactivation with Cur. However,
Quishida et al. [43] verified no significant reduction in total biomass of multispecies biofilm of C. albicans, C. glabrata, and $S$. mutans after API mediated by Photodithazine. This difference in the results may be attributed to the photosensitizers used, suggesting that Cur presents a greater capacity for disarticulation of the biofilm structure.

The CLSM images showed that after API with Cur $120 \mu \mathrm{M}$, there was a visible increase in cells stained red when compared with their respective controls ( 24 and $48 \mathrm{~h}$ ), suggesting that there may be cell photodamage and penetration of the fluorochrome PI into the cell. This result is in agreement with those observed by Quishida et al. [43], who also verified a visible increase in red cells after API mediated by Photodithazine in multispecies biofilm of C. albicans, C. glabrata, and S. mutans. Moreover, after API with CUR $120 \mu \mathrm{M}$, the 24-h biofilm visibly presented a higher number of red cells when compared with the 48-h biofilm. As regards the biofilm thickness, the control group ( $\mathrm{P}-\mathrm{L}-$ ) of 24-h biofilm presented a thickness of $20 \mu \mathrm{M}$, while the control group $\left(\mathrm{P}-\mathrm{L}^{-}\right)$of 48 -h biofilm presented a thickness of $23.5 \mu \mathrm{M}$, showing an increase in thickness of the 48 -h biofilm. In a previous study [43], when biofilm with the same microbial species were formed in wells of a polystyrene plate, the thickness of 48-h biofilm was $19 \mu \mathrm{M}$, thinner than that of the biofilm in the present study, possibly due to the difference in the substrates used for biofilm adherence and formation. Furthermore, the 24-h biofilm treated only with Cur $120 \mu \mathrm{M}$ showed a visible increase in the quantity of red cells when compared with the control group $(\mathrm{P}-\mathrm{L}-)$ of $24 \mathrm{~h}$, suggesting the antimicrobial activity of Cur even in conditions of the absence of illumination in a less mature biofilm [33-35]. However, no quantitative analysis of the images obtained was performed, which limits interpretation of the images.

Although the results showed a significant difference after API, they could not be extrapolated to a clinical scenario. The in vitro biofilm is cultivated with a high concentration of microorganisms $\left(10^{7}-10^{8} \mathrm{CFU} / \mathrm{mL}\right)$ compared with microbial load found in clinical infections $\left(10^{4}-10^{5} \mathrm{CFU} / \mathrm{mL}\right.$ for Candida spp. and S. mutans) [8]. Furthermore, the synergism among the species in a multispecies biofilm may favor the microorganisms against the antimicrobial therapy. This issue needs further investigations. In addition, few studies are available evaluating the efficacy of API against multispecies biofilm. Therefore, the results obtained in this study may direct future studies in order to improve methods and strategies against complex biofilms.

\section{Conclusion}

According to the results of this study and considering its limitations, it can be concluded that both 24-h and 48-h biofilms were susceptible to API mediated by Cur in the concentrations 
evaluated and light dose of $37.5 \mathrm{~J} / \mathrm{cm}^{2}$. No difference in the photoinactivation of the biofilm was verified among the concentrations of Cur evaluated. However, no other doses of light and pre-illumination times were evaluated.

Acknowledgments This work was supported by São Paulo Research Foundation-FAPESP (Grant 2011/09054), Centro de Pesquisa em Óptica e Fotônica-CEPOF-CEPID (Grant 13/07276-1).

Compliance with ethical standards

Conflict of interest None declared

\section{References}

1. Chandra J, Mukherjee PK, Leidich SD, Faddoul FF, Hoyer LL, Douglas LJ et al (2001) Antifungal resistance of candidal biofilms formed on denture acrylic in vitro. J Dent Res 80:903-908

2. Gendreau L, Loewy ZG (2011) Epidemiology and etiology of denture stomatitis. J Prosthodont 20:251-260

3. Budtz-Jörgensen E (1990) Etiology, pathogenesis, therapy, and prophylaxis of oral yeast infections. Acta Odontol Scand 48:61-69

4. Perezous LF, Flaitz CM, Goldschmidt ME, Engelmeier RL (2005) Colonization of Candida species in denture wearers with emphasis on HIV infection: a literature review. J Prosthet Dent 93:288-293

5. Monsenego P (2000) Presence of microorganisms on the fitting denture complete surface: study 'in vivo'. J Oral Rehabil 27:708713

6. Theilade E, Budtz-Jorgensen E (1988) Predominant cultivable microflora of plaque on removable dentures in patients with dentureinduced stomatitis. Oral Microbiol Immunol 3:8-13

7. Baena-Monroy T, Moreno-Maldonado V, Franco-Martínez F, Aldape-Barrios B, Quindós G, Sánchez-Vargas LO (2005) Candida albicans, Staphylococcus aureus and Streptococcus mutans colonization in patients wearing dental prosthesis. Med Oral Patol Oral Cir Bucal 10:27-39

8. Ribeiro DG, Pavarina AC, Dovigo LN, Mima EG, Machado AL, Bagnato VS, Vergani CE (2012) Photodynamic inactivation of microorganisms present on complete dentures. A clinical investigation. Lasers Med Sci 27:161-168

9. Costerton JW, Stewart PS, Greenberg EP (1999) Bacterial biofilms: a common cause of persistent infections. Science 284:1318-1322

10. Hoyle BD, Williams LJ, Costerton JW (1993) Production of mucoid exopolysaccharide during development of Pseudomonas aeruginosa biofilms. Infect Immun 61:777-780

11. Lamfon H, Al-Karaawi Z, McCullough M, Porter SR, Pratten J (2005) Composition of in vitro denture plaque biofilms and susceptibility to antifungals. FEMS Microbiol Lett 242:345-351

12. Ramage G, Vandewalle K, Wickes BL, Lopez-Ribot JL (2001) Characteristics of biofilm formation by Candida albicans. Rev Iberoam Micol 18:163-170

13. Kumamoto CA, Vinces MD (2005) Alternative Candida albicans life styles: growth on surfaces. Annu Rev Microbiol 59:113-133

14. Lewis K (2001) Mini review. Riddle of Biofilm Resistance. Antimicrob Agents Chemother 45:999-1007

15. Banting DW, Greenhorn PA, McMinn JG (1995) Effectiveness of a topical antifungal regimen for the treatment of oral candidiasis in older, chronically ill, institutionalized, adults. J Can Dent Assoc 61(199-200):203-205

16. Banting DW, Hill SA (2001) Microwave disinfection of dentures for the treatment of oral candidiasis. Spec Care Dentist 21:4-8
17. Ellepola AN, Samaranayake LP (2000) Antimycotic agents in oral candidosis: an overview: 2. Treatment of oral candidosis. Dent Update 27(165-70):172-174

18. Kulak Y, Arikan A, Delibalta N (1994) Comparison of three different treatment methods for generalized denture stomatitis. J Prosthet Dent 72:283-288

19. Barchiesi F, Arzeni D, Del Prete MS, Sinicco A, Falconi Di Francesco L, Pasticci MB, Lamura L, Nuzzo MM, Burzacchini F, Coppola S, Chiodo F, Scalise G (1998) Fluconazole susceptibility and strain variation of Candida albicans isolates from HIV-infected patients with oropharyngeal candidosis. J Antimicrob Chemother 41:541-548, Erratum in: J Antimicrob Chemother 1998; 42: 413

20. Goldman GH, da Silva Ferreira ME, dos Reis ME, Savoldi M, Perlin D, Park S, Godoy Martinez PC, Goldman MH, Colombo AL (2004) Evaluation of fluconazole resistance mechanisms in Candida albicans clinical isolates from HIV-infected patients in Brazil. Diagn Microbiol Infect Dis 50:25-32

21. Hunter KD, Gibson J, Lockhart P, Pithie A, Bagg J (1998) Fluconazole-resistant Candida species in the oral flora of fluconazole-exposed HIV-positive patients. Oral Surg Oral Med Oral Pathol Oral Radiol Endod 85:558-564

22. White TC, Marr KA, Bowden RA (1998) Clinical, cellular, and molecular factors that contribute to antifungal drug resistance. Clin Microbiol Rev 11:382-402

23. Allison RR, Mota HC, Bagnato VS, Sibata CH (2008) Bionanotechnology and photodynamic therapy-state of the art review. Photodiagnosis Photodyn Ther 5:19-28

24. Cieplik F, Tabenski L, Buchalla W, Maisch T (2014) Antimicrobial photodynamic therapy for inactivation of biofilms formed by oral key pathogens. Front Microbiol 5:405

25. Konopka K, Goslinski T (2007) Photodynamic therapy in dentistry. J Dent Res 86:694-707

26. Dovigo LN, Pavarina AC, Carmello JC, Machado AL, Brunetti IL, Bagnato VS (2011) Susceptibility of clinical isolates of Candida to photodynamic effects of curcumin. Lasers Surg Med 43:927-934

27. Bliss JM, Bigelow CE, Foster TH, Haidaris CG (2004) Susceptibility of Candida species to photodynamic effects of Photofrin. Antimicrob Agents Chemother 48:2000-2006

28. Cormick MP, Alvarez MG, Rovera M, Durantini EM (2009) Photodynamic inactivation of Candida albicans sensitized by tri- and tetra-cationic porphyrin derivatives. Eur J Med Chem 44:1592-1599

29. Giroldo LM, Felipe MP, de Oliveira MA, Munin E, Alves LP, Costa MS (2009) Photodynamic antimicrobial chemotherapy (PACT) with methylene blue increases membrane permeability in Candida albicans. Lasers Med Sci 24:109-112

30. Munin E, Giroldo LM, Alves LP, Costa MS (2007) Study of germtube formation by Candida albicans after photodynamic antimicrobial chemotherapy (PACT). J Photochem Photobiol B 88:16-20

31. So CW, Tsang PW, Lo PC, Seneviratne CJ, Samaranayake LP, Fong WP (2010) Photodynamic inactivation of Candida albicans by BAM-SiPc. Mycoses 53:215-220

32. Souza RC, Junqueira JC, Rossoni RD, Pereira CA, Munin E, Jorge AO (2010) Comparison of the photodynamic fungicidal efficacy of methylene blue, toluidine blue, malachite green and low-power laser irradiation alone against Candida albicans. Lasers Med Sci 25:385-389

33. Souza SC, Junqueira JC, Balducci I, Koga-Ito CY, Munin E, Jorge AO (2006) Photosensitization of different Candida species by low power laser light. J Photochem Photobiol B 83:34-38

34. Wilson M, Mia N (1993) Sensitisation of Candida albicans to killing by low-power laser light. J Oral Pathol Med 22:354-357

35. Chabrier-Roselló Y, Foster TH, Perez-Nazario N, Mitra S, Haidaris CG (2005) Sensitivity of Candida albicans germ tubes and biofilms 
to photofrin-mediated phototoxicity. Antimicrob Agents Chemother 49:4288-4295

36. Donnelly RF, McCarron PA, Tunney MM, David Woolfson A (2007) Potential of photodynamic therapy in treatment of fungal infections of the mouth. Design and characterisation of a muco adhesive patch containing toluidine blue O. J Photochem Photobiol B 86:59-69

37. Junqueira JC, Martins J da S, Faria RL, Colombo CE, Jorge AO (2009) Photodynamic therapy for the treatment of buccal candidiasis in rats. Lasers Med Sci 24:877-884

38. Teichert MC, Jones JW, Usacheva MN, Biel MA (2002) Treatmentof oral candidiasis with methylene blue-mediated photodynamic therapy in an immunodeficient murine model. Oral Surg Oral Med Oral Pathol Oral Radiol Endod 93:155-160

39. Soares BM, da Silva DL, Sousa GR, Amorim JC, de Resende MA, Pinotti M, Cisalpino OS (2009) In vitro photodynamic inactivation of Candida spp. growth and adhesion to buccal epithelial cells. J Photochem Photobiol B 94:65-70

40. Dovigo LN, Pavarina AC, de Oliveira Mima EG, Giampaolo ET, Vergani CE, Bagnato VS (2011) Fungicidal effect of photodynamic therapy against fluconazole-resistant Candida albicans and Candida glabrata. Mycoses 54:123-130

41. Dovigo LN, Pavarina AC, Ribeiro AP, Brunetti IL, Costa CA, Jacomassi DP, Bagnato VS, Kurachi C (2011) Investigation of the photodynamic effects of curcumin against Candida albicans. Photochem Photobiol 87:895-903

42. Dovigo LN, Carmello JC, Carvalho MT, Mima EG, Vergani CE, Bagnato VS, Pavarina AC (2013) Photodynamic inactivation of clinical isolates of Candida using Photodithazine ${ }^{\circledR}$. Biofouling 29:1057-1067

43. Quishida CC, Carmello JC, Mima EG, Bagnato VS, Machado AL, Pavarina AC (2015) Susceptibility of multispecies biofilm to photodynamic therapy using Photodithazine ${ }^{\mathbb{R}}$. Lasers Med Sci 30:685-694

44. Pereira CA, Romeiro RL, Costa AC, Machado AK, Junqueira JC, Jorge AO (2011) Susceptibility of Candida albicans, Staphylococcus aureus, and Streptococcus mutans biofilms to photodynamic inactivation: an in vitro study. Lasers Med Sci 26:341-348

45. Epstein J, Sanderson IR, Macdonald TT (2010) Curcumin as a therapeutic agent: the evidence from in vitro, animal and human studies. Br J Nutr 103:1545-1557

46. Martins CVB, Silva DL, Neres ATM, Magalhães TFF, Watanabe GA, Modolo LV, Sabino AA, de Fatima A, de Resende MA (2009) Curcumin as a promising antifungal of clinical interest. $\mathrm{J}$ Antimicrob Chemother 63:337-339

47. Priyadarsini KI (2009) Photophysics, photochemistry and photobiology of curcumin: studies from organic solutions, bio-mimetics and living cells. J Photochem Photobiol C: Photochem Rev 10:81-95

48. Sharma RA, Gescher AJ, Steward WP (2005) Curcumin: the story so far. Eur J Cancer 41:1955-1968

49. Bruzell EM, Morisbak E, Tønnesen HH (2005) Studies on curcumin and curcuminoids. XXIX. Photo induced cytotoxicity of curcumin in selected aqueous preparations. Photochem Photobiol Sci 4:523-530

50. Koon HK, Leung AWN, Yue KKM, Mak NK (2006) Photodynamic effect of curcumin on NPC/CNE2 cells. J Environ Pathol Toxicol Oncol 25:205-215

51. Tonnesen HH, Vries H, Karlsen J, Van Henegouwen GB (1987) Studies on Curcumin and curcuminoids IX: investigation of photobiological activity of curcumin using bacterial indicator systems. J Pharm Sci 76:371-373

52. Pileggi G, Wataha JC, Girard M, Grad I, Schrenzel J, Lange N, Bouillaguet S (2013) Blue light-mediated inactivation of Enterococcus faecalis in vitro. Photodiagn Photodyn Ther $10: 134-140$

53. Araújo NC, Fontana CR, Bagnato VS, Gerbi ME (2014) Photodynamic antimicrobial therapy of curcumin in biofilms and carious dentine. Lasers Med Sci 29:629-635

54. Zissis AJ, Polyzois GL, Yannikakis SA, Harrison A (2000) Roughness of denture materials: a comparative study. Int J Prosthodont 13:136-140

55. Millsap KW, Bos R, van der Mei HC, Busscher HJ (1999) Adhesion and surface-aggregation of Candida albicans from saliva on acrylic surfaces with adhering bacteria as studied in a parallel plate flow chamber. Antonie Van Leeuwenhoek 75:351-359

56. Pereira-Cenci T, Del Bel Cury AA, Crielaard W, Tem Cate JM (2008) Development of candida-associated denture stomatitis: new insights. J Appl Oral Sci 16:86-94

57. Chandra J, Kuhn DM, Mukherjee PK, Hoyer LL, McCormick T, Ghannoum MA (2001) Biofilm formation by the fungal pathogen Candida albicans: development, architecture, and drug resistance. J Bacteriol 183:5385-5394

58. Dovigo LN, Carmello JC, de Souza Costa CA, Vergani CE, Brunetti IL, Bagnato VS, Pavarina AC (2013) Curcuminmediated photodynamic inactivation of Candida albicans in a murine model of oral candidiasis. Med Mycol 51:243-251

59. Mima EG, Pavarina AC, Neppelenbroek KH, Vergani CE, Spolidorio DM, Machado AL (2008) Effect of different exposure times on microwave irradiation on the disinfection of a hard chairside reline resin. J Prosthodont 17:312-317

60. Seneviratne CJ, Silva WJ, Jin LJ, Samaranayake YH, Samaranayake LP (2009) Architectural analysis, viability assessment and growth kinetics of Candida albicans and Candida glabrata biofilms. Arch Oral Biol 54:1052-1060

61. Silva S, Henriques M, Martins A, Oliveira R, Williams D, Azeredo J (2009) Biofilms of non-Candida albicans Candida species: quantification, structure and matrix composition. Med Mycol 47:681-689

62. Quishida CC, Mima EG, Dovigo LN, Jorge JH, Bagnato VS, Pavarina AC (2015) Photodynamic inactivation of a multispecies biofilm using Photodithazine $\left({ }^{\circledR}\right)$ and LED light after one and three successive applications. Lasers Med Sci 30:2303-2312

63. Garcia-Gomes AS, Curvelo JA, Soares RM, Ferreira-Pereira A (2012) Curcumin acts synergistically with fluconazole to sensitize a clinical isolate of Candida albicans showing a MDR phenotype. Med Mycol 50:26-32 